\title{
Impact of waiting time on hepatocellular carcinoma progression in patients undergoing curative tumour ablation
}

\author{
Daniel Yuxuan Ong, Zhong Yun Lee, Uei Pua \\ Department of Diagnostic Radiology, Tan Tock Seng Hospital, Singapore, Singapore
}

Contributions: (I) Conception and design: All authors; (II) Administrative support: All authors; (III) Provision of study materials or patients: All authors; (IV) Collection and assembly of data: All authors; (V) Data analysis and interpretation: All authors; (VI) Manuscript writing: All authors; (VII) Final approval of manuscript: All authors.

Correspondence to: Uei Pua, MBBS, FRCR, MMed, FAMS, FCIRSE, FSIR. Department of Diagnostic Radiology, Tan Tock Seng Hospital, 11 Jalan Tan Tock Seng, Singapore 308433, Singapore. Email: druei@yahoo.com.

Background: A feared consequence to delay in oncological treatment includes disease progression. This study aims to evaluate the relationship between waiting time for ablative therapy in patients with hepatocellular carcinoma (HCC), and the outcomes of local tumour progression, or new HCC foci.

Methods: Between January 2011 to July 2017, 215 patients with HCC underwent ablative (microwave and radiofrequency) procedures. Demographic information, and duration between diagnosis on imaging and ablative procedure were recorded. Follow-up imaging data were analysed to assess for development of either new HCC, or local tumour progression. The median waiting time to ablative therapy was 42 days, hence, patients were separated into two groups: wait time $<42$ days versus wait time $\geq 42$ days. Simple cox regression was conducted to explore the association between wait time and the clinical outcomes of new HCC or local tumour progression. Survival analyses for outcomes of new HCC or local tumour progression were also compared between the two groups using log-rank test. All the statistical analyses were two sided and $\mathrm{P}$ value of less than 0.05 was considered as statistically significant.

Results: Hazard ratio for local tumour progression was $1.002(0.996,1.007) \mathrm{P}=0.579$, while hazard ratio for new HCC foci was $1.002(0.998,1.005) \mathrm{P}=0.373$. There was no statistically significant difference when comparing the two groups (wait time $<42$ versus $\geq 42$ days) for survival estimates for local tumour progression $\mathrm{P}=0.346$, and for new HCC $\mathrm{P}=0.680$.

Conclusions: This study demonstrates that delay in HCC ablative therapy is not associated with significant risk of local tumour progression, or new HCC foci.

Keywords: Waiting; time; hepatocellular; carcinoma; progression

Submitted Dec 31, 2020. Accepted for publication Sep 30, 2021.

doi: 10.21037/qims-20-1411

View this article at: https://dx.doi.org/10.21037/qims-20-1411

\section{Introduction}

Hepatocellular carcinoma (HCC) is one of the cancers with the highest mortality rates worldwide (1). The standard of care for HCC utilises the Barcelona Clinic Liver Cancer (BCLC) staging system (2). Broadly, treatment modalities include ablation, resection, transplantation, chemoembolization, systemic therapy and best supportive care. Cases with very early stage HCC (single nodule $<2 \mathrm{~cm}$ ) or early stage HCC (single or 3 nodules $\leq 3 \mathrm{~cm}$ ) are amenable to ablative therapies, of which options include radiofrequency ablation (RFA) or microwave ablation (MWA) (3,4).

Many malignancies show linear or exponential growth 
models (5-7), and HCC has been posited to have one of the fastest growing incidences. Deferred cancer treatment can result in tumour progression and worsened survival (8-10). Current literature on the effect of treatment delays on HCC are limited to single centre studies, and displays varying outcomes (11-16). Wait times to hepatic ablative therapy has been previously studied. For instance, Brahmania et al. revealed a median time of 96 days in their study population. There are many reasons to treatment delays. For instance, patients must be adequately informed about the disease, the possible treatment options, and their effect on oncological outcomes and quality of life, institution schedules, obtaining insurance clearance, etc. (5). Brahmania et al. delineated the reasons for hepatic ablative delay into four sub-groups: patient factors, diagnostic radiology factors, interventional factors and hepatology factors. Overall, there is no agreed upon target wait times for management of HCC with ablative therapies. In general, early active therapy is believed to be necessary (16).

The aim of this study is to evaluate the relationship between waiting time to ablative therapy, and outcomes of development of new HCC foci, or local tumour progression.

\section{Methods}

\section{Study patients \& design}

The study was conducted in accordance with the Declaration of Helsinki (as revised in 2013). This is an Institutional Review Board approved study with waiver of informed consent (NHG DSRB 2020/00130). A retrospective cohort study was conducted. Utilizing our institution's electronic medical records, we identified ablative procedures (including both microwave and radiofrequency ablation) for liver lesions suggestive of HCC, from January 2011 to July 2017. There were a total of 322 patients with 602 liver lesions.

Standard computed tomography (CT) guided ablative techniques were utilised in the authors' institution, and commonly used ablation equipment includes Emprint Ablation System with Thermosphere Technology (Covidien, Boulder, CO) and Cool-Tip RF system (Covidien, Boulder, $\mathrm{CO}$ ), for instance. All patients are referred for ablation following multi-disciplinary tumour board discussion. Contrast enhanced cross-sectional imaging (magnetic resonance imaging or $\mathrm{CT}$ ) is used for pre-operative planning. The procedure is performed under ultrasound
(US) and CT guidance to obtain an ablative margin of 0.5 to $1 \mathrm{~cm}$. For MWA, a single antenna is positioned within the tumour and ablation is performed for 8.5 to $10 \mathrm{~min}$ at $100 \mathrm{~W}$ as per manufacturer instruction. For RFA, between 1 to 3 electrodes are placed within the tumour with impedance-based ablation performed up to 12 minutes. Immediate post-procedure contrast enhanced CT or contrast enhanced US was performed for assessment of ablation margins. Additional overlapping ablation zone is obtained where necessary.

Liver lesions with the following features were subsequently excluded: metastatic from primary malignancy elsewhere ( $\mathrm{n}=93,15.4 \%)$, having undergone previous treatment $(\mathrm{n}=88,14.6 \%)$, being part of combination treatment $(\mathrm{n}=53,8.8 \%)$, unsuccessful ablations $(\mathrm{n}=11$, $1.8 \%)$, and incomplete data $(\mathrm{n}=9,1.5 \%)$. Eventually, we identified 348 liver lesions from 215 patients.

In patients with multiple liver lesions, we analysed lesions that were diagnosed earlier. If date of diagnosis was the same, only the lesion ablated first was included, or the larger lesion (if date of ablation is the same). Ultimately, we identified 215 liver lesions, and analysed them.

Demographic data and wait time were recorded. The authors define wait time as the duration between date of diagnosis on imaging and ablation. Follow-up imaging data was reviewed by a single radiologist, to assess for HCC progression, defined by the authors as either progression of local tumour or development of new HCC foci. The authors define progression of local tumour as HCC progression within or peri-ablation zones, whilst new HCC was defined as development of new intrahepatic HCC foci.

\section{Statistical analysis}

Data was analysed using IBM SPSS version 19.0 (IBM Corp., Armonk, NY). Descriptive statistics were used to present the baseline characteristics as well as the clinical outcomes of the participants. The median waiting time to ablative therapy was 42 days, hence, patients were separated into two groups: wait time $<42$ days versus wait time $\geq 42$ days. Independent $t$-test, Pearson chi-square test and Fisher exact test were used to explore the difference in baseline characteristics between the two groups.

Simple cox-regression was conducted to explore the association between wait time and the clinical outcomes in view of the time-to-event nature of data. The survival estimates for local tumour progression and new HCC foci for patient with different wait times ( $<42$ days, and 
Table 1 Baseline characteristics of the participants $(n=215)$

\begin{tabular}{|c|c|c|c|c|}
\hline Variables & All & $<42$ days & $\geq 42$ days & $P$ value \\
\hline Age, mean (SD) & $65.56(10.04)$ & $68.49(10.68)$ & $68.62(9.43)$ & $0.923^{\mathrm{a}}$ \\
\hline \multicolumn{5}{|l|}{ Gender, n (\%) } \\
\hline Female & $55(25.6)$ & $23(21.7)$ & $32(29.4)$ & $0.214^{\mathrm{b}}$ \\
\hline \multicolumn{5}{|l|}{ Clinical outcomes } \\
\hline \multicolumn{5}{|l|}{ Mode of diagnosis, n (\%) } \\
\hline MRI & $183(85.1)$ & $90(84.9)$ & $93(85.3)$ & $0.215^{\mathrm{c}}$ \\
\hline CT & $28(13.0)$ & $16(15.1)$ & $12(11.0)$ & \\
\hline Lesion dimension 1, mean (SD) & $1.89(0.74)$ & $1.96(0.76)$ & $1.82(0.71)$ & $0.185^{\mathrm{a}}$ \\
\hline Lesion dimension 2, mean (SD) & $1.75(0.69)$ & $1.86(0.73)$ & $1.65(0.64)$ & $0.025^{\mathrm{a}}$ \\
\hline Time from diagnosis to treatment, median (IQR) & $42.00(29.00)$ & NA & NA & NA \\
\hline
\end{tabular}

${ }^{a}$, independent sample $t$-test; ${ }^{b}$, Pearson chi-square test; ${ }^{c}$, Fisher-Exact test. SD, standard deviation; MRI, magnetic resonance imaging; $\mathrm{CT}$, computed tomography; IQR, interquartile range.

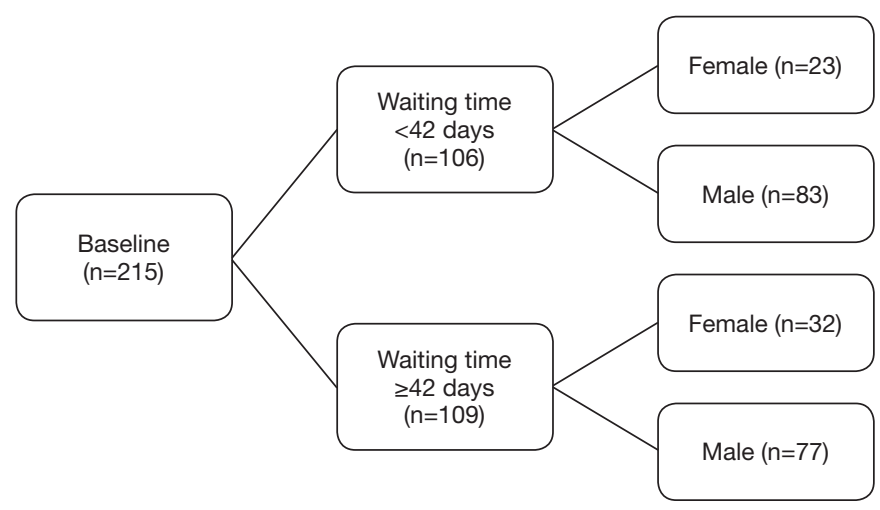

Figure 1 Sequential diagram of distribution of waiting time.

$\geq 42$ days) were compared using log-rank test. All of the statistical analysis was two-sided and $\mathrm{P}$ value of less than 0.05 was considered as statistically significant.

\section{Results}

A total of 215 independent liver lesions were identified in 215 unique patients, with baseline characteristics as shown in Table 1 and Figure 1. Notably, the median wait time was identified as 42 days (range, $0-445$ days) (Table 1).
Clinical outcomes of the patients are as shown in Table 2. There were 152 patients with imaging done within $12-18$ months. Of these, there were 32 patients (14.9\%) with local tumour progression, and 61 patients $(28.4 \%)$ with new HCC foci. According to the latest follow-up data, 46 patients $(21.4 \%)$ had local tumour progression and 116 patients $(54.0 \%)$ had new HCC foci.

Hazard ratio for local tumour progression was 1.002 (0.996, 1.007), $\mathrm{P}=0.579$, while hazard ratio for new HCC was $1.002(0.998,1.005), \mathrm{P}=0.373$ (Table 3). There is no 
Table 2 Clinical outcome of the participants $(n=215)$

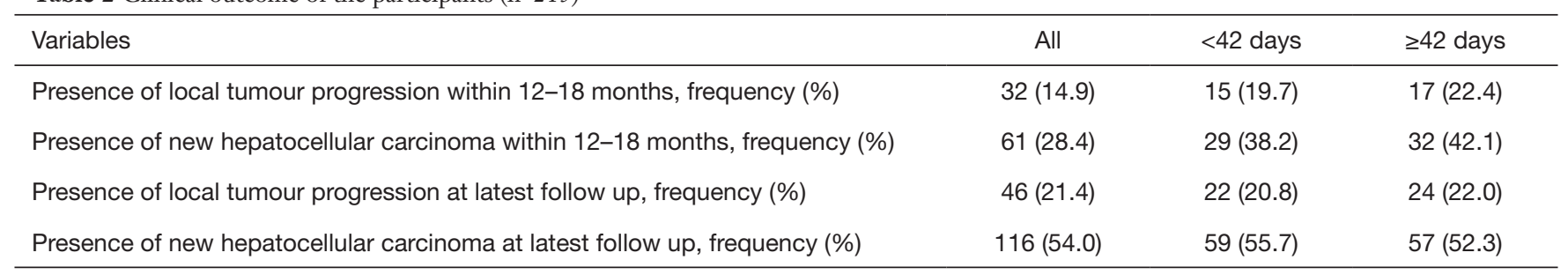

Table 3 Survival analysis of wait time ( $<42$ or $\geq 42$ days) predicting the outcomes at latest follow-up

\begin{tabular}{lccc}
\hline \multirow{2}{*}{ Clinical outcomes } & All & \multicolumn{2}{c}{ Univariate analysis } \\
\cline { 3 - 4 } & & Hazard ratio & $95 \% \mathrm{Cl}$ \\
\hline Presence of local tumour progression & $46(21.4)$ & 1.002 & $0.996,1.007$ \\
Presence of new hepatocellular carcinoma & $116(54.0)$ & 1.002 & $0.998,1.005$ \\
\hline
\end{tabular}

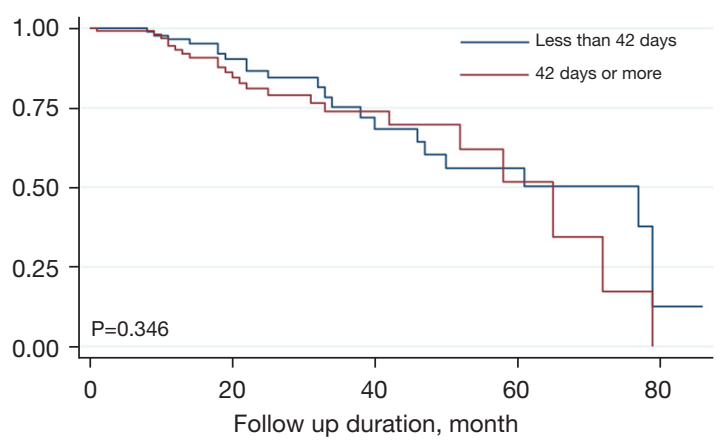

Figure 2 Kaplan-Meier survival estimates for local tumour progression (LTP), comparing between patients with waiting times $<42$ or $\geq 42$ days.

statistically significant difference in survival estimates when comparing the two groups (wait time $<42$ versus $\geq 42$ days) for local tumour progression, $\mathrm{P}=0.346$, and for new HCC foci, $\mathrm{P}=0.680$ (Figures 2,3).

Hence, our study shows no significant association between wait time and local tumour progression or new HCC foci.

\section{Discussion}

HCC is one of the cancers with the highest mortality rates worldwide. There will inadvertently be waiting time to treatment due to varying reasons. A concern of treatment delay would be disease progression. For patients diagnosed with HCC, delays as little as 3 months in therapeutic

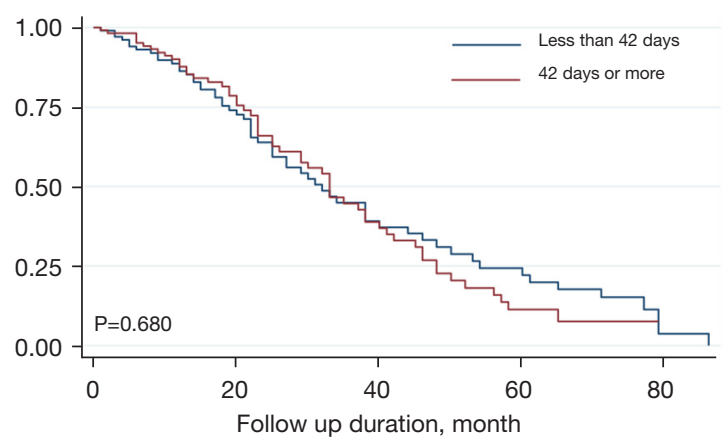

Figure 3 Kaplan-Meier survival estimates for new hepatocellular carcinoma (HCC).

follow-up can allow for significant tumour growth (17).

Existing literature have looked extensively into the impact of waiting times on many oncologic conditions, with varying results. For instance, in colon cancer, Hangaard showed that there was no association between treatment delay and reduced overall survival in colon cancer patients (18). For prostate cancer, Fossati showed that the effect of delayed treatment was significantly evident in high-risk patients only (5).

Current literature on the effect of treatment delays on HCC outcomes are largely limited to single centre studies (11-16). In this study, we demonstrated that patients with waiting times $<42$ or $\geq 42$ days does not have significant differences HCC progression in terms of local tumour progression or findings of new intrahepatic HCC foci. This 
is in concordance with what Akce and $\operatorname{Lim}(11,12)$ found, that treatment delays were not associated with increased risk of death from HCC. The authors posit that a possible explanation for this non-intuitive finding would be that the median waiting times for our institution is relatively low, being that of 42 days. This is in comparison with the median wait times of 96 days for example, in a 2017 study that explores the effect of wait time to RFA on HCC outcomes (13). This 2017 study, along with several others, found that incremental wait times are associated with poorer outcomes of increased risk of tumour progression and death (13-16).

There are several limitations to this study. Firstly, this is a single centre, retrospective cohort study. To add on, this study focuses only on patients amenable to ablative therapies. We have also only analysed single liver lesion from each patient. In addition, the authors acknowledge that there are several pertinent factors that are not taken into consideration for the study. These include etiology of underlying liver disease, liver function reserve, Child-Pugh scoring, tumour markers, patient comorbidities, cancer staging, for instance. This was inadvertent, as a significant proportion of patients were found to be lacking these during data collection.

As the healthcare systems come under increasing pressure from the COVID-19 pandemic (19), clinicians and researchers need to change and adapt management of oncology accordingly. For instance, Bartlett and Zhao $(20,21)$ posits that patients with early HCC should receive ablative therapy in preference over surgical resections. Practically, this may not be achievable in the short run, as resources would need to be diverted to expanding the services of the relevant interventional units.

Whilst efforts are being increasingly placed to improve wait times in the healthcare system, our study shows that the negative outcomes of increased wait time may be overemphasized. This study provides insight that while cancer treatment should ideally be initiated as soon as possible, minor delays due to unavoidable operational restrictions may not yield significant adverse outcomes. Nevertheless, improvement of healthcare-related efficiency is a positive trend that the authors are in support of.

\section{Conclusions}

This study demonstrates that delay in ablative therapy in the context of HCC is not associated with a significant risk of local tumour progression, or new HCC foci.

\section{Acknowledgments}

The authors acknowledge the following individual for providing her expertise on statistical analyses: Chien Joo Lim, Master of Science, Clinical Reseach \& Innovation Office, Tan Tock Seng Hospital, Singapore.

Funding: None.

\section{Footnote}

Conflicts of Interest: All authors have completed the ICMJE uniform disclosure form (available at https://dx.doi. org/10.21037/qims-20-1411). The authors have no conflicts of interest to declare.

Ethical Statement: The authors are accountable for all aspects of the work in ensuring that questions related to the accuracy or integrity of any part of the work are appropriately investigated and resolved. The study was conducted in accordance with the Declaration of Helsinki (as revised in 2013). The study was approved by institutional board of National Healthcare Group (No. 2020/00130) and individual consent for this retrospective analysis was waived.

Open Access Statement: This is an Open Access article distributed in accordance with the Creative Commons Attribution-NonCommercial-NoDerivs 4.0 International License (CC BY-NC-ND 4.0), which permits the noncommercial replication and distribution of the article with the strict proviso that no changes or edits are made and the original work is properly cited (including links to both the formal publication through the relevant DOI and the license). See: https://creativecommons.org/licenses/by-nc-nd/4.0/.

\section{References}

1. Zhu RX, Seto WK, Lai CL, Yuen MF. Epidemiology of Hepatocellular Carcinoma in the Asia-Pacific Region. Gut Liver 2016;10:332-9.

2. Llovet JM, Di Bisceglie AM, Bruix J, Kramer BS, Lencioni R, Zhu AX, Sherman M, Schwartz M, Lotze M, Talwalkar J, Gores GJ; Panel of Experts in HCCDesign Clinical Trials. Design and endpoints of clinical trials in hepatocellular carcinoma. J Natl Cancer Inst 2008;100:698-711.

3. Llovet JM, Fuster J, Bruix J; Barcelona-Clínic Liver Cancer Group. The Barcelona approach: diagnosis, 
staging, and treatment of hepatocellular carcinoma. Liver Transpl 2004;10:S115-20.

4. Vietti Violi N, Duran R, Guiu B, Cercueil JP, Aubé C, Digklia A, Pache I, Deltenre P, Knebel JF, Denys A. Efficacy of microwave ablation versus radiofrequency ablation for the treatment of hepatocellular carcinoma in patients with chronic liver disease: a randomised controlled phase 2 trial. Lancet Gastroenterol Hepatol 2018;3:317-25.

5. Fossati N, Rossi MS, Cucchiara V, Gandaglia G, Dell'Oglio P, Moschini M, Suardi N, Dehò F, Montorsi F, Schiavina R, Mottrie A, Briganti A. Evaluating the effect of time from prostate cancer diagnosis to radical prostatectomy on cancer control: Can surgery be postponed safely? Urol Oncol 2017;35:150.e9-150.e15.

6. Iversen LH, Antonsen S, Laurberg S, Lautrup MD. Therapeutic delay reduces survival of rectal cancer but not of colonic cancer. Br J Surg 2009;96:1183-9.

7. Thompson MR, Heath I, Swarbrick ET, Wood LF, Ellis BG. Earlier diagnosis and treatment of symptomatic bowel cancer: can it be achieved and how much will it improve survival? Colorectal Dis 2011;13:6-16.

8. Waaijer A, Terhaard CH, Dehnad H, Hordijk GJ, van Leeuwen MS, Raaymakers CP, Lagendijk JJ. Waiting times for radiotherapy: consequences of volume increase for the TCP in oropharyngeal carcinoma. Radiother Oncol 2003;66:271-6.

9. Jensen AR, Nellemann HM, Overgaard J. Tumor progression in waiting time for radiotherapy in head and neck cancer. Radiother Oncol 2007;84:5-10.

10. Pulte D, Brenner H. Changes in survival in head and neck cancers in the late 20 th and early 21 st century: a period analysis. Oncologist 2010;15:994-1001.

11. Akce M, Sansgiry S, Temple SL, Davila J, Sada Y. The effect of treatment delay on survival in patients with hepatocellular cancer. J Clin Oncol 2017;35:e15645.

12. Lim C, Bhangui P, Salloum C, Gómez-Gavara C, Lahat E, Luciani A, Compagnon P, Calderaro J, Feray C, Azoulay D. Impact of time to surgery in the outcome of patients with liver resection for BCLC 0-A stage hepatocellular carcinoma. J Hepatol 2017. [Epub ahead of print]. doi: 10.1016/j.jhep.2017.09.017.

Cite this article as: Ong DY, Lee ZY, Pua U. Impact of waiting time on hepatocellular carcinoma progression in patients undergoing curative tumour ablation. Quant Imaging Med Surg 2022;12(2):1499-1504. doi: 10.21037/qims-20-1411
13. Brahmania M, Ahmed O, Kelley M, Wong D, Kowgier M, Khalili K, Beecroft R, Renner EL, Shah H, Feld J, Janssen HLA, Sherman M. Wait Time for Curative Intent Radio Frequency Ablation is Associated with Increased Mortality in Patients with Early Stage Hepatocellular Carcinoma. Ann Hepatol 2017;16:765-71.

14. Singal AG, Waljee AK, Patel N, Chen EY, Tiro JA, Marrero JA, Yopp AC. Therapeutic delays lead to worse survival among patients with hepatocellular carcinoma. J Natl Compr Canc Netw 2013;11:1101-8.

15. Tsai WC, Kung PT, Wang YH, Kuo WY, Li YH. Influence of the time interval from diagnosis to treatment on survival for early-stage liver cancer. PLoS One 2018;13:e0199532.

16. Huo TI, Huang YH, Chiang JH, Wu JC, Lee PC, Chi CW, Lee SD. Survival impact of delayed treatment in patients with hepatocellular carcinoma undergoing locoregional therapy: is there a lead-time bias? Scand J Gastroenterol 2007;42:485-92.

17. Kubota K, Ina H, Okada Y, Irie T. Growth rate of primary single hepatocellular carcinoma: determining optimal screening interval with contrast enhanced computed tomography. Dig Dis Sci 2003;48:581-6.

18. Hangaard Hansen C, Gögenur M, Tvilling Madsen M, Gögenur I. The effect of time from diagnosis to surgery on oncological outcomes in patients undergoing surgery for colon cancer: A systematic review. Eur J Surg Oncol 2018;44:1479-85.

19. The Lancet Oncology. COVID-19: global consequences for oncology. Lancet Oncol 2020;21:467.

20. Bartlett DL, Howe JR, Chang G, Crago A, Hogg M, Karakousis G, Levine E, Maker A, Mamounas E, McGuire K, Merchant N, Shibata D, Sohn V, Solorzano C, Turaga K, White R, Yang A, Yoon S; Society of Surgical Oncology. Management of Cancer Surgery Cases During the COVID-19 Pandemic: Considerations. Ann Surg Oncol 2020;27:1717-20.

21. Zhao H, Du S, Cai J, Mao Y. Recommendations for medical care of oncological patients during the COVID-19 epidemic: experiences from China. Updates Surg 2020;72:235-6. 